OPEN ACCESS

Edited by:

Enrique Martínez-Meyer

Universidad Nacional Autónoma de

México, Mexico

Reviewed by:

Glen John Van Der Kraak,

University of Guelph, Canada

Andres Garcia,

Universidad Nacional Autónoma de

México, Mexico

*Correspondence: Frieder Graef fgraef@zalf.de

Specialty section:

This article was submitted to Agroecology and Land Use Systems,

a section of the journal

Frontiers in Environmental Science

Received: 21 April 2016

Accepted: 17 January 2018

Published: 14 February 2018

Citation:

Berger G, Graef F, Pallut B, Hoffmann J, Brühl CA and Wagner N (2018) How Does Changing Pesticide

Usage Over Time Affect Migrating Amphibians: A Case Study on the Use of Glyphosate-Based Herbicides in German Agriculture Over 20 Years.

Front. Environ. Sci. 6:6.

doi: 10.3389/fenvs.2018.00006

\section{How Does Changing Pesticide Usage Over Time Affect Migrating Amphibians: A Case Study on the Use of Glyphosate-Based Herbicides in German Agriculture Over 20 Years}

\author{
Gert Berger ${ }^{1}$, Frieder Graef ${ }^{1 *}$, Bernhard Pallut ${ }^{2}$, Jörg Hoffmann ${ }^{3}$, Carsten A. Brühl ${ }^{4}$ and \\ Norman Wagner ${ }^{5}$ \\ ${ }^{1}$ Leibniz Centre for Agricultural Landscape Research, Müncheberg, Germany, ${ }^{2}$ Formerly at Federal Research Centre for \\ Cultivated Plants, Institute for Strategies and Technology Assessment, Julius Kühn-Institut, Kleinmachnow, Germany, \\ ${ }^{3}$ Federal Research Centre for Cultivated Plants, Institute for Strategies and Technology Assessment, Julius Kühn-Institut, \\ Kleinmachnow, Germany, ${ }^{4}$ Institute for Environmental Sciences, University of Koblenz-Landau, Landau, Germany, \\ ${ }^{5}$ Department of Biogeography, Trier University, Trier, Germany
}

Since its introduction in 1974, the use of glyphosate in agriculture has been continuously increasing; however, the application modes of this herbicide have been changing. Therefore, glyphosate-based herbicides can be used as an appropriate indicator for assessing how changes in pesticide application modes affect wild-living organisms in agricultural landscapes over time. Amphibians that migrate through arable fields may be exposed to the chemicals applied to field crops. Using data on the temporal coincidence of four amphibian populations with glyphosate applications from a three-year investigation in northeast Germany as well as data on the application of glyphosate to field crops in German agriculture over 20 years, we estimated the species-specific increasing rates of coincidence likelihoods during this period. The overall consumption of glyphosate used in German agriculture between 1992 and 2012 increased by a factor of 5.7, while the species-specific coincidence likelihood increased from 2.2 to 6.1, respectively. Our results reveal the highest increases in coincidence for both adult and juvenile great crested newt (Triturus cristatus) and fire-bellied toad (Bombina bombina). Adults and juveniles of moor frog (Rana arvalis) and adults of spadefoot toad (Pelobates fuscus) were subjected to moderate increases, with rates ranging from 3.2 to 3.6; in contrast, juvenile individuals of $P$. fuscus showed small increases. We suggest that the risk assessments of pesticide application (in this case, glyphosate) should not only consider the present use at the time of authorization but also consider changes in application modes over time that may lead to increases in potential exposure of non-target organisms, such as amphibians.

Keywords: amphibians, migration, glyphosate, application practice, temporal coincidence, crop fields 


\section{INTRODUCTION}

One of the suggested major drivers for the global decline of amphibians is the intensification of agriculture and its associated activities (Collins and Storfer, 2003; Hayes et al., 2006; Boone et al., 2007; Mann et al., 2009; Brühl et al., 2013). In addition to the loss of habitats in agricultural areas, agrochemical pollution, which often interacts with other factors like climate change, UV-B radiation, emerging infectious diseases and alien species (Collins and Storfer, 2003; Stuart et al., 2008), is detrimental to amphibians (Mann et al., 2009). The impacts of agrochemicals on amphibians in water bodies (Xu and Oldham, 1997; Relyea, 2009; Biga and Blaustein, 2013) and on land (Oldham et al., 1997; Mann and Bidwell, 1999; Marco et al., 2001; Howe et al., 2004; Cauble and Wagner, 2005; Relyea, 2005; Bernal et al., 2009; Dinehart et al., 2009; Belden et al., 2010; Brühl et al., 2013) have been thoroughly studied and documented (Govindarajulu, 2008; Mann et al., 2009; Relyea, 2011; Wagner et al., 2013).

Glyphosate-based formulations have been shown to be toxic, especially during the aquatic life stages of amphibians, and often the commonly added surfactant POEA (polyethoxylated tallow amine) is mainly responsible for adverse effects (Giesy et al., 2000; Brausch and Smith, 2007; Brausch et al., 2007; Moore et al., 2012). Taking the particular risks of POEA into consideration, POEAfree glyphosate-based formulations have increasingly been used in German agriculture since 2013 (Rossberg, 2015a). The effects of glyphosate-based herbicides (hereafter referred to as GBH) on amphibians are formulation, species and life-stage specific and include osmotic instability, delayed or accelerated development, reduced size at metamorphosis, malformations, stress, and death (Wagner et al., 2013). Severe toxic effects caused by direct overspraying of GBH on terrestrial juvenile stages of different anuran species have been revealed and documented in laboratory studies (Relyea, 2005; Bernal et al., 2009; Dinehart et al., 2009); however, scientific evidence on the toxicity of GBH on amphibians in field conditions is rare. We did not reflect the real impact of $\mathrm{GBH}$ on amphibian populations, and we did not consider interception by the crop canopy; thus, real field exposure was not studied. Rather, we used the increasing crop-specific usage of $\mathrm{GBH}$ in German agriculture over time and the temporal overlap of pesticide applications to crops with when amphibian populations are present in fields to determine the species-specific potential risk.

Globally, glyphosate (hereafter referred to as GLY) was introduced to agriculture in 1974 (BCPC, 2003) and was registered in Germany in 1975 (BVL, 2009). Between 1999 and 2008, the annual growth rate of its use in Germany was approximately 20\% (Steinmann et al., 2012). GLY applications cover a wide range of crops and agronomic measures (Dill et al., 2010). Its modes of application, however, are currently changing. In the Americas and other parts of the world, the increase in the use of GLY correlates with the increase in the cultivation of genetically modified GLY-tolerant crops (Duke and Powles, 2008); however, in Germany, most genetically modified crops are still awaiting approval (Wagner and Lötters, 2013). Additionally, the present GLY usage in Germany is not only restricted to weed control but also promotes the entire production process, including reducing soil tillage and seedbed preparation, preventing erosion, controlling crop ripening (siccation) and harvesting, and managing stubble (Dill et al., 2010; Steinmann et al., 2012). These changing modes of herbicide application over time may alter the exposure risk of amphibians.

While the effects of GLY and GBH on larval amphibians have been well studied (see the review by Wagner et al., 2013 and more recent studies, e.g., Vincent and Davidson, 2015; Baier et al., 2016; Güngördü et al., 2016; Rissoli et al., 2016; Soloneski et al., 2016), there have been few studies on the effects of GBH on terrestrially active amphibians (oral exposure: McComb et al., 2008; direct over-spraying: Relyea, 2005; Bernal et al., 2009; Dinehart et al., 2009). Edge et al. (2011, 2013) exposed newly metamorphosed juveniles within the land-water transitional zone and found little or no effects on juvenile survival. Other studies exposed amphibians in terrestrial life-stages to GBH that was dissolved in water (Mann and Bidwell, 1999; Lajmanovich et al., 2015). Very little is known about the effects of GLY and its formulations on amphibians moving between breeding ponds and terrestrial habitats during non-breeding periods during the year (Relyea, 2005; Berger et al., 2013). Hence, it is important to analyze and quantify changes in the likelihood of the potential exposure of amphibian populations to GLY in crop fields over long periods. Berger et al. (2013) carried out an extensive field survey on the temporal coincidence of four typical amphibian species with GLY. Using expert estimations on the modes of GLY usage in agriculture over 20 years, we calculated the speciesand age-level specific increases in the probability of temporal coincidence of amphibian populations.

We hypothesized that the overall increase in GLY consumption in German agriculture between 1992 and 2012 affected amphibian populations to various extents. The rates of increase of coincidence likelihood of the amphibian populations are different and are dependent on species and age level; thus, we can identify focal species that are particularly coincident in fields with GLY applications in German agriculture.

\section{MATERIALS AND METHODS}

\section{Reference Year and Investigation Periods}

Annual crop production and GLY sales for agriculture varied over the tenure of 20 years (i.e., 1992-2012). Therefore, we considered three average values for this period by considering the cultivation of arable crops $\times 1000$ ha, which is abbreviated in this paper as Tha, and the GLY sales ( $t$ ) for the periods of 1991-1993, 2001-2003, and 2011-2013; these data were used as a reference. These average values are referred to as investigation year 1992, 2002, and 2012, respectively. Further, based on a field survey that covered a wide range of agricultural farm situations throughout Germany and was valid for the reference year 2009, Steinmann et al. (2012) calculated the relative share of crop area treated with the three GLY application modes. The authors supported their calculated data by comparing them with the GLY sales and consumption in German agriculture during this reference year. All extrapolations and investigations of our work are linked to this reference year. 


\section{Glyphosate Sale and Usage in German Agriculture from 1988 to 2013}

Statistical data on the sale and usage of GLY in German agriculture were available, though data were of various qualities. We derived data on GLY usage from 2009 onwards by analyzing the annual reports of BVL (Bundesamt für Verbraucherschutz und Landwirtschaft), which is the regulating authority for pesticides in Germany (BVL, 2014a,c). The consumption between 1995 and 2008 was derived from annual data on the sale of organophosphorus herbicides, which was specifically delivered by the German authority Federal Office of Consumer Protection and Food Safety (BVL, 2014b). Due to specific marketing rights of a single company during the period between 1988 and 1994, the BVL authority provided only an average value of the annual sale (BVL, 2014b). Applying the assessed trend function for the annual increase $(\mathrm{yc}=166.45 \mathrm{x}+129.7$; for 1988: $x=1$, and for 1994: $x=7$ ), which was revealed by pre-analyses, we derived the annual values of the consumption of GLY from 1988 to 1994 . We verified our estimations by visually analyzing the extrapolated values on the chart. The amount of GLY sold to professional users during the investigation years are based on the average sales from three consecutive years. Of the total estimated sales, $90 \%$ was used by farmers (Rossberg, $2015 \mathrm{~b}$ ), and the remaining $10 \%$ was used by other professionals belonging to horticulture, viniculture, railway companies and municipalities.

\section{Expert Estimation and Validation of Glyphosate Usage Per Application Scheme and Crop}

The usage schemes of GLY in agriculture for the investigation years 1992, 2002, and 2012 were jointly assessed by consensus of four experts with knowledge of GLY use in agriculture. First, the experts listed the changes in 1992, 2002, and 2012 as compared to the reference year 2009. For instance, (a) "most farmers did not apply glyphosate to winter barley stubbles in 1992" and (b) "due to increasing importance of reduced soil tillage to winter crops from 1992 to 2002 and to 2012, the stubble application on winter barley continuously increased." Second, these identified changes were translated into relative numbers. For instance, compared to 2009, the application areas in 1992, 2002, and 2012 were estimated to be $10 \%$ (factor of $0.1-2009$ ), $70 \%$ (factor of $0.7-$ 2009 ) and $110 \%$ (factor of 1.1-2009), respectively. Third, based on the numbers relative to 2009 , we calculated the proportion of area where GLY was applied, considering all application schemes and crops for the identified study years. Multiplying this value by the total cultivation area of crops, we derived the area of crops treated with GLY for each investigation year and included the application modes. Finally, using the methodology of Steinmann et al. (2012), the application rate of GLY per hectare, and the application modes for all crops, we calculated the amount of GLY applied in the investigation years. Then, we calculated the total amount of GLY usage in German agriculture for each investigation year and compared it to the corresponding statistical data on GLY sales and consumption in German agriculture. When the deviance between the calculated values and the real values was less than $5 \%$, we considered the values to be satisfactory; in contrast, higher deviations were used to iteratively adapt the estimates that the experts felt less confident about.

\section{Field Data on the Temporal Coincidence of Amphibians with Glyphosate Applications to Crops}

The quantitative field data available for the temporal coincidence of amphibian populations with the application of GLY on arable fields were provided by a field survey carried out between 2006 and 2008 in a study area located $50 \mathrm{~km}$ east of Berlin, Germany (Berger et al., 2013). This landscape has intensive agriculture use and is pond rich, so we analyzed four typically occurring amphibian species [fire-bellied toad (Bombina bombina, Linnaeus, 1761), moor frog (Rana arvalis, Nilsson, 1842), spadefoot toad (Pelobates fuscus, Laurenti, 1768) and northern crested newt (Triturus cristatus, Laurenti, 1768)] by using fence trapping during the annual migration periods. These amphibian species cover a wide range of different migration periods. Forty-nine drift fences, which consisted of 26 open, 10$\mathrm{m}$-long, cross-shaped fences, and 23 enclosures were installed between field machinery tramlines. The cross-shaped fences were regularly distributed in a $400 \times 400 \mathrm{~m}$ grid to record amphibian migration activity in fields, and they encircled biotopes (i.e., wood lots, small water bodies) located at the edges of fields or completely within fields. Depending on the direction of migration, either the inner or outer traps were analyzed. Captured individuals were released $10-15 \mathrm{~m}$ from the opposite site of the fence.

We included three different application modes (e.g., presowing or pre-emerging application in spring, siccation in summer, and pre-harvesting and stubble management in late summer/autumn prior to crop sowing) and six major field crops (maize, triticale, winter barley, winter rape, winter rye and winter wheat); additionally, we used the four amphibian species listed above and their age-specific coincidence values for two $\mathrm{DT}_{50}$ values of GLY (i.e., 12 and 47 days) separately. These values allowed the derivation of important indicators for the co-occurrence and potential exposure of amphibian populations (Berger et al., 2013). The three GLY application modes used in Steinmann et al. (2012) partially differed from the modes applied by Berger et al. (2013). Thus, each of our crop GLY application modes was adjusted to match the "Steinmann system." The use of the two $\mathrm{DT}_{50}$ levels ("Dissipation Time." i.e., the halflife of the active ingredient of GLY in soils) as well as the average of the single coincidence values for each field was done according to Berger et al. (2013). The $\mathrm{DT}_{50}$ values of GLY ranged from 2 to 197 days, with a typical field half-life of 47 days (Miller et al., 2010). The $\mathrm{DT}_{50}$ estimates were available for the POEA surfactant only (i.e., 21-41 days; but not for other substances added to the formulation; Giesy et al., 2000). Hence, the $\mathrm{DT}_{50}$ values for GLY must serve as proxies for GBH. We calculated and applied coincidence values for each GLY application scheme and for each crop as averages of the two $\mathrm{DT}_{50}$ levels. 


\section{Calculating the Species and Age-Class Specific Changes of Coincidence Values}

Changes in the coincidence likelihood between amphibian populations and the application of GLY to field crops depend on (a) the increase in GLY application area per application scheme over time and (b) the species and their age-level-specific share of the amphibian populations. To find a species and age-specific indicator value suitable for explaining changes over years, we multiplied the coincidence values and the GLY application area, which enabled the calculation of the coincidence likelihood Equation (1).
2012. For pre-sowing application, compared to the values from 2009 , we estimated an additional increase of 1.2 for winter wheat and an increase of 1.1 for both oilseed rape and corn.

\section{Calculated Area of Glyphosate Applied on Arable Land and GLY Consumption in German Agriculture}

The total area of GLY application in German agriculture, including grassland (not shown), was $\approx 740$ Tha in $1992 ; \approx 2.930$ Tha in 2002; and $\approx 4.250$ Tha in 2012. Based on the area of GLY application and the estimated application rates per crop, the

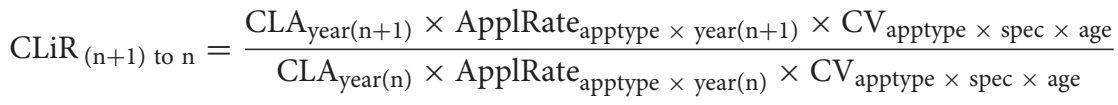

$\mathrm{CLiR}(\mathrm{n}+1)$ to $\mathrm{n}$ : coincidence likelihood ratio between one year $(\mathrm{n})$ and the following $(\mathrm{n}+1)$. CLA year $\ldots$ : crop land area per year (i.e., average values of three consecutive years: 1992: 1991-1993; 2002: 2001-2003; 2012: 2011-2013, [Tha]); ApplRate appltypex year ...: GLY application rate of crop land per year and period [\%]; CV appltypexspecxage: average coincidence values of two migration periods and two $\mathrm{DT}_{50}$ values for 4 amphibian species and 2 age classes [\%].

The ratio of the obtained products indicate the likelihood of an increase in coincidence between periods. The analyses were performed for the four amphibian species, their two age levels, and the two migration periods (i.e., from and to ponds).

\section{RESULTS}

\section{Overall Glyphosate Sales and Consumption in German Agriculture Over the Last 20 Years}

In Germany, GLY usage by professional applicators (e.g., agriculture, horticulture, railway companies, municipalities) increased from $956 \mathrm{t}$ of active substance in 1992 to $5415 \mathrm{t}$ of active substance in 2012 (BVL, 2014a). Thus, the consumption in 2012 was 5.7 times higher than the consumption 20 years ago. In 2002, approximately $3740 \mathrm{t}$ GLY was applied, corresponding to a 3.9-fold increase compared to 1992 and a 1.5 -fold increase from 2002 to 2012. In terms of agricultural use, we assumed $90 \%$ of the total consumption was by professionals (860, 3.365 and $4.873 \mathrm{t}$, respectively), leading to the same increase in values between periods.

\section{Expert Estimations on the Relative Changes of Glyphosate Application Modes to Arable Crops Over 20 Years}

The factors relative to the GLY application in 2009, as estimated by experts, varied between the crops and periods (Figure 1). Except for maize, which had a factor of 0.5 , the pre-sowing applications to all other crops in 1992 were estimated to be approximately 0.1 of the application value of 2009. In both 2002 and 2012, the application values for this crop surpassed the application value of 2009. In 2002, the other range of crop factors (relative to 2009) varied from 0.7 to 0.8 , and this value was 1.0 in consumption of GLY in agriculture was $845 \mathrm{t}, 3.340 \mathrm{t}$, and $4.865 \mathrm{t}$ for 1992, 2002, and 2012, respectively. These values differed between -0.2 and $-1.7 \%$ from the statistically grounded sale of GLY to agricultural buyers.

The areas with most of the 6 main crops, i.e., winter wheat (wwt), silage maize (mze), oilseed rape (wra), winter barley (wbl) and winter rye/triticale (wry/trc), considered for amphibian coincidence analyses increased over 20 years. The increase from 1992 to 2012 ranged from 1.3 to 1.6 , though the value for winter barley fell outside this range. The area of maize increased the most between 2002 and 2012, with a rate of 1.8 during this 10-year period.

The application area of these 6 crops increased from 663 Tha in 1992 to 2286 Tha in 2002 and to 3461 Tha in 2012, encompassing between 81 and $94 \%$ of the total area where GLY was applied on arable land. The GLY application area increased from by factor 5.2 between 1992 and 2012, by a factor of 3.4 between 1992 and 2002, and by a factor of 1.5 between 2002 and 2012. The GLY application area was largely different between periods and plants (Figure 2). Wwt, wra, and wbl covered large areas with the steepest increases occurring between 1992 and 2002. This contrasts with the GLY application area of mze, which particularly increased between 2002 and 2012, but never reached the application area of wwt, wra and wbl.

\section{Allocation of Glyphosate to Application Modes of Crops Considered for Amphibian Coincidence}

Except for pre-harvesting applications for mze, the GLY application areas for all other crops with different application modes increased. The average rate of increase of 9.1 was exceeded for wwt, wra, and rye/trc for all three applications modes. For presowing (ps/pe) and pre-harvesting (ph) in wwt and for ps/pe in wra, we found a 16 -fold increase in rates. When comparing the rates of increase between 1992 and 2002 with those between 2002 and 2012, we mostly found higher values during the first period. As shown for ps/pe and ph in wry/trc, the values were as much as 8 -fold higher. With respect to the size of application area, stubble application (sa) of wra was always ranked first during the entire 20 -year period, though ranks 2 through 4 occasionally changed over time. From 2002 to 2012, we found the same combinations of crops and application modes in these rank positions, albeit in 


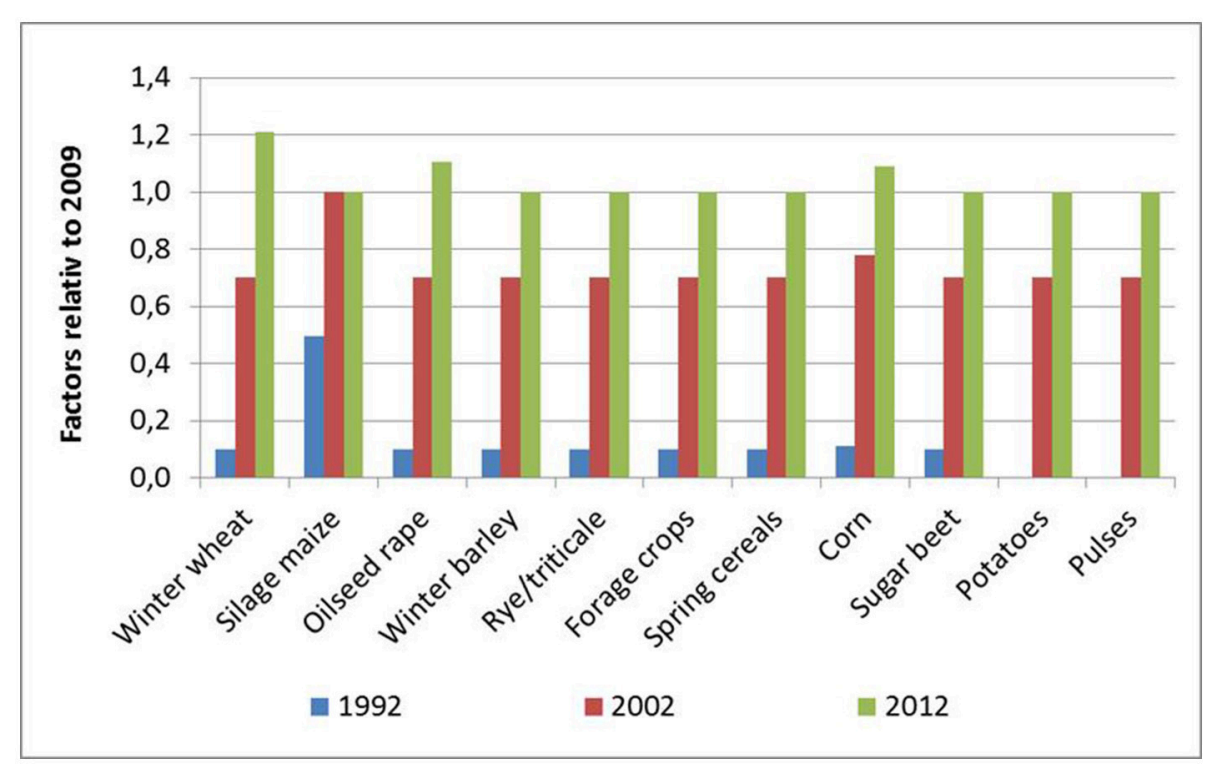

FIGURE 1 | Expert estimations of the relative deviances from the reference year 2009 (Steinmann et al., 2012) on the amount of GLY applied in pre-sowing applications of $\mathrm{GBH}$ to arable crops in the three investigation years.

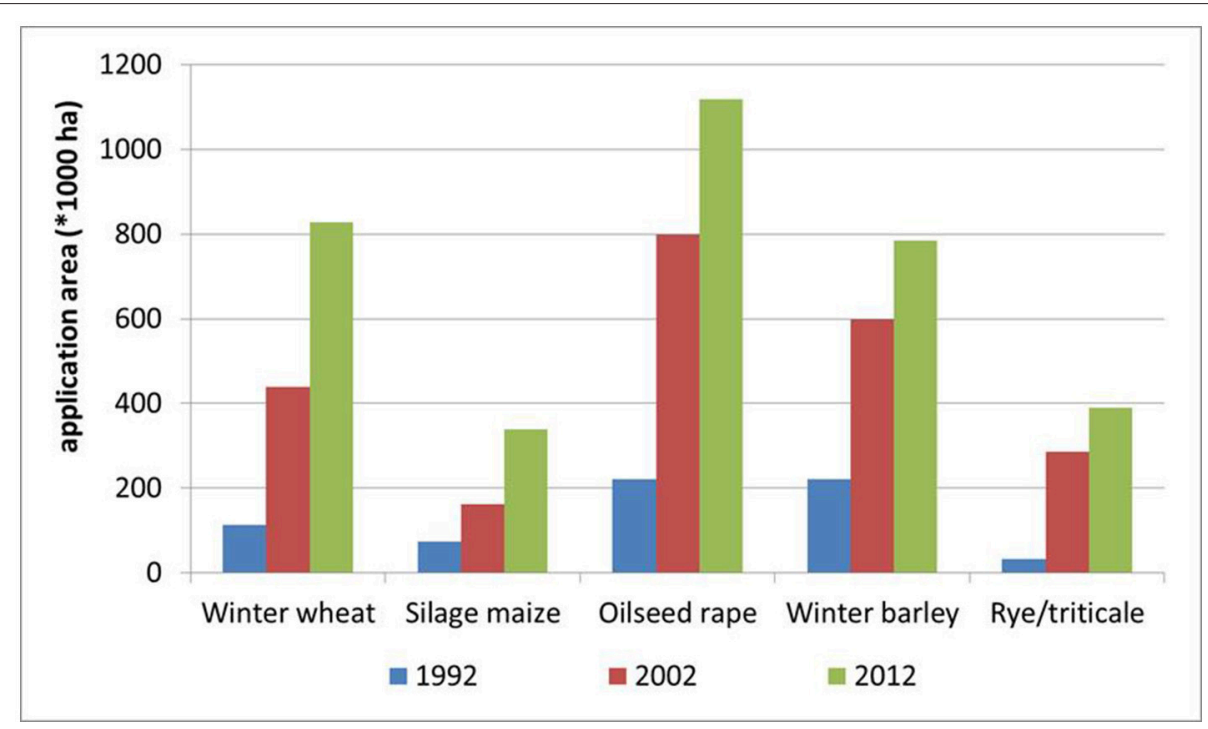

FIGURE 2 | Total GLY application area for each crop considered for amphibian coincidence during the three investigation periods over 20 years.

different orders. In 1992, ps/pe in mze was in rank 4, and ph in wbl was in rank 2. Both lost these ranked positions in following years.

\section{Amphibian-Specific Increase of Coincidence Likelihood}

The rise of GLY in agriculture during the 20-year period led to increasing rates of coincidence likelihood of amphibians from 2.2 to 6.1 (Table 1). We found the amphibian coincidence likelihood increased by an average of a factor of 4.1 between 1992 and 2012, 2.6 between 1992 and 2002, and 1.5 between
2002 and 2012. The coincidence likelihood rates of increase for adults of all four species migrating to ponds were about onethird lower than the average coincidence likelihoods observed between 1992 and 2002. The same was found for adults of $P$. fuscus and for juveniles of $R$. arvalis and P. fuscus that migrated from ponds. In contrast, adults and juveniles of $T$. cristatus and $B$. bombina largely exceeded the average increases. Their coincidence likelihoods were about one-half higher than the averages and almost twice as high than the other amphibian groups. Between 2002 and 2012, the increases in coincidence likelihoods for the investigated amphibian groups were different 
TABLE 1 | Cumulative product values and rate of increase according to migration, age and species (bold* indicates values above mean).

\begin{tabular}{|c|c|c|c|c|c|c|c|c|}
\hline \multirow[t]{2}{*}{ Migration } & \multirow[t]{2}{*}{ Age } & \multirow{2}{*}{$\begin{array}{l}\text { Species } \\
\text { Period }\end{array}$} & \multicolumn{3}{|c|}{$\begin{array}{l}\text { Cumulative product values (GLY application } \\
\text { area * coincident population share) }\end{array}$} & \multicolumn{3}{|c|}{ Rate of increase } \\
\hline & & & 1992 & 2002 & 2012 & 1992-2002 & 2002-2012 & 1992-2012 \\
\hline \multirow[t]{4}{*}{ To ponds } & Adults & R. arvalis & 1.5334 & 2.7762 & 4.9398 & 1.8 & $1.8^{\star}$ & 3.2 \\
\hline & & T. cristatus & 2.4904 & 4.5087 & 8.0225 & 1.8 & $1.8^{\star}$ & 3.2 \\
\hline & & P. fuscus & 1.4154 & 2.5624 & 4.5595 & 1.8 & $1.8^{\star}$ & 3.2 \\
\hline & & B. bombina & 4.2799 & 7.7486 & 13.7875 & 1.8 & $1.8^{\star}$ & 3.2 \\
\hline \multirow[t]{8}{*}{ From ponds } & Adults & T. cristatus & 13.2085 & 51.5473 & 80.2051 & $3.9^{\star}$ & 1.6 & $6.1^{*}$ \\
\hline & & P. fuscus & $2.543,5$ & 4.6048 & 8.1936 & 1.8 & $1.8^{\star}$ & 3.2 \\
\hline & & B. bombina & 13.9743 & 52.0846 & 78.7004 & $3.7^{*}$ & 1.5 & $5.6^{\star}$ \\
\hline & Juveniles & Rana arvalis & 8.0988 & 20.9970 & 29.5561 & $2.6^{*}$ & 1.4 & 3.6 \\
\hline & & Triturus cristatus & 14.8296 & 60.0357 & 89.6121 & $4.0^{\star}$ & 1.5 & $6.0^{\star}$ \\
\hline & & Pelobates fuscus & 10.5586 & 17.3677 & 23.4559 & 1.6 & 1.4 & 2.2 \\
\hline & & Bombina bombina & 7.3688 & 30.4893 & 42.7882 & $4.1^{*}$ & 1.4 & $5.8^{\star}$ \\
\hline & & & & Mean & & 2.6 & 1.6 & 4.1 \\
\hline
\end{tabular}

than the values from the preceding decade (Table 1). The rate of increase of coincidence likelihoods for adults of all species migrating into ponds and for adults of $P$. fuscus leaving ponds were above average. However, for all juveniles and for adults of $T$. cristatus and B. bombina, we found increases of coincidence likelihoods that were equal or lower than the average value.

The increases of coincidence likelihoods for the entire investigation period (i.e., 1992-2012) were similar to the changes between 1992 and 2002, though the changes were at various extents (Table 1). With almost a 6-fold rate of increase, we found the highest values for adults and juveniles of T. cristatus; in contrast, the coincidence likelihood of juveniles of $P$. fuscus increased only by a factor of 2.2.

The increases in coincidence of likelihoods for species and age levels were found to vary between 1.4 and 6.1. For $T$. cristatus and B. bombina, the highest increases were recorded between 1992 and 2002, though we found higher coincidence likelihood increases for adults of $P$. fuscus and $R$. arvalis during the second period. Generally, for the former two species, we found profoundly lower rates of increase compared to the others, and, except for P. fuscus, we found higher increases for juveniles than for adults over the 20 -year period.

\section{DISCUSSION}

To date, there are no existing methodologies or studies on long-term changes in GLY application modes and the linkage to amphibian migration. We used coincidence values from an extensive three-year investigation on both the temporal application of GLY to crops and the share of migrating amphibian populations in fields. Based on that, we partially refer to the potential exposure while acknowledging that the interception by the plant canopy and the specific field conditions were not considered but should be subjects of further research. For example, soil or litter remarkably reduced the adverse effects on over-sprayed amphibians in terrestrial life stages in two laboratory studies (Bernal et al., 2009; Dinehart et al., 2009). However, laboratory data show that the active ingredient (GLY) of the $\mathrm{GBH}$ permeates the skin of edible frogs (Pelophylax kl. esculentus) 26-times faster than it permeates pig skin (Quaranta et al., 2009). The acute and chronic effects of GBH uptake in the terrestrial life stages of amphibians are documented. For example, $79 \%$ of tested juvenile anurans died within one day after direct over-spraying with a commercial GBH at recommended application rates in North America (Relyea, 2005). Additionally, $30 \%$ of individuals of several tested anuran species died within $24 \mathrm{~h}$ after direct over-spraying at usual application rates of a $\mathrm{GBH}$ used in coca plant eradication in Colombia (Bernal et al., 2009). Based on results from studies using larvae, different GBH formulations pose different risks for terrestrial amphibian life stages. Depending on the tested formulation, mortality ranged from 0 to $80 \%$ in over-sprayed Great Plains toads (Bufo cognatus) and New Mexico spadefoots (Spea multiplicata) (Dinehart et al., 2009). Hence, the fast absorption of GLY should not be the most important cause of observed effects, as adjuvants are usually mainly responsible instead (Wagner et al., 2013). However, to date, there are no data on absorption time and rates of added substances (like POEA surfactants) in amphibians. From the tropics, there is also an anecdotal report that caecilians with burn-like wounds were found 5-7 h after Roundup applications in a tea plantation in Sri Lanka (de Silva, 2009). Finally, sublethal low doses of a GBH induced neurotoxicity, oxidative stress and immunological depression in exposed Argentine toads (Rhinella arenarum) (Lajmanovich et al., 2015).

The coincidence values used in our calculations are based on data from a single investigation area in northeast Germany. Though the field management and species coincidence values may vary between regions, we presume that the principal linkage between the timing of GLY applications to crops and amphibian behavior is similar on large spatial scales. It is very likely that the species and age levels of amphibians that were more coincident 
to glyphosate applications in our investigation area will be more coincident in other regions too. This is because both the migration modes of the species (i.e., early or late migrating species) and the crop cultivation systems with respect to GLY applications are widely similar. Additionally, both the timing of agricultural cultivation and the timing of amphibian activity are driven by climate and weather conditions and may lead to a uniform time shift (Lötters et al., 2014). Thus, we are confident the observed trends are valid for arable regions in the northern lowlands of Germany where glyphosate is applied and amphibians are present. We validated the expert estimates on GLY usage in German agriculture using the statistical data on GLY agricultural consumption. Since the official statistical landuse data of Germany includes an error of $2-10 \%$ (Steinmann et al., 2012), we considered deviances lower than $2 \%$ from the real sales to be appropriate.

Our results indicate that generalizing the increase in sales and consumption of pesticides, in this case GLY, in agriculture is inappropriate for characterizing the potential exposure of specific organisms. While the overall GLY consumption increased by a factor of 5.7 between 1992 and 2012, the rates of species coincidence likelihoods varied widely. Both the crop-specific GLY use among various applications and the changes in the cultivation area of crops over time increased the coincidence likelihoods, though these changes were at different extents. With a 16-fold increase in GLY application area, the application mode of pre-sowing to wwt showed highest change. Since there were no scientifically supported coincidence values for this application mode, its impact on the increase of coincidence likelihood of species was not analyzed.

We found the highest ranks among the area of GLY application to crops and periods for the following two modes, pre-sowing/pre-emerging and stubble applications. Both are closely related to reduced or conservation tillage without plowing. Over time, glyphosate has become the backbone of no-till agriculture (Duke and Powles, 2008; Yadav et al., 2013). Together with the control of green biomass (volunteers and weeds, Agropyron repens in particular), these are considered to be the main drivers of GLY application (Raubuch and Schieferstein, 2002; Nail et al., 2007). In German crop rotations, rewardable winter cereals, such as winter wheat, winter barley and triticale, often follow winter rape (Steinmann and Dobers, 2013), and in accordance to our findings, field cultivation is often conducted in combination with GLY application. In 2009, winter rape was considered the major sink of GLY in Germany (Steinmann et al., 2012). This was confirmed in our study for the years 2002 and 2012. In 2009/2010, approximately 39\% of German arable land was cultivated by reduced tillage, covering approximately 4.469 Mio ha, underlining the importance of this type of soil management (Destatis, 2011).

For many years, pre-harvesting application (siccation) was common in winter barley. With the objectives of cleaning weeds and volunteers from the crop, controlling the timing of harvest, and better adjusting harvest technique siccation, the use of GLY has become increasingly prominent in other arable crops too (Cook et al., 2010). In terms of winter wheat, our analyses indicate up to 17-fold increases in GLY application areas over the 20-year period, with the highest application level in 2012. Nonetheless, even in 2012, the total area of pre-harvesting application in Germany did not exceed 5\% of the arable land. Thus, this was still far below what is found in the UK, where $40-80 \%$ of cereals and oilseed rape are regularly treated for siccation (Cook et al., 2010). Starting in 2014, pre-harvesting siccation regulations changed; for instance, the application depends on the specific crop canopy conditions (BVL, 2014a). This may lead to a reduced application area.

The change in crop area over time is another important driver that affects the increase in GLY usage in agriculture. Some economically profitable crops, such as winter wheat, oilseed rape and silage maize, have increased, leading to narrower crop rotations and fewer crop species (Steinmann and Dobers, 2013; Destatis, 2015). Reducing the number of crops leads to more intensive peak-periods for conducting field cultivation and increases demands for higher working rates. For stubble cultivation, GLY application appears to be appropriate (Nail et al., 2007; Steinmann et al., 2012). A small number of crops linked with reduced tillage and a monotonic herbicide application scheme with active ingredients that are based on similar effective mechanisms may also cause resistant weeds that are hard to control (Weedscience, 2015). Higher rates and an increase in the application of herbicides, including GLY, are then necessary (Beckie, 2006). Narrow crop rotations may promote plant pests and diseases (Steinmann and Dobers, 2013). Controlling the green bridge between two successive crops to prevent the spread of pests or disease is particularly essential and often typically done using GLY.

With respect to the year 2009, Steinmann et al. (2012) characterized GLY applications "as a routine application facilitating many agronomical purposes.” GLY emerged as a weed control instrument and shifted to a multifunctional agronomical tool that replaced traditional practices; it can also be used to save labor and machinery input. Our results confirmed the author's conclusion for Germany and indicated what today's wide GLY usage (for many agronomic purposes) may mean for wildliving organisms. Together with its worldwide use in genetically modified crops, GLY has become the best-selling herbicide in many countries and may be used as a sole herbicide (Duke and Powles, 2008). In Asia, for instance, there are many countries that are rich in amphibian diversity but are also experiencing rapid growth in agricultural production, and the consumption of glyphosate and other herbicides is increasing. Though it is known that, in most cases, applications of agrochemicals overlap with the breeding activities of amphibians in agro-ecosystems on the Indian subcontinent (Hegde and Krishnamurthy, 2014), there is a complete dearth of information on the rate of coincidence of migrating amphibian populations under this agrochemical environment (Mann et al., 2009). Therefore, the present work could be a guideline for those countries where plant protection products are increasingly being used and are leading to species-specific increases in potential exposure of amphibian populations.

The semi-steep increase in coincidence likelihoods with amphibians indicates the need for further research. Specifically, since European endangered and protected species, such as $T$. 
cristatus and B. bombina (EU, 1992), are experiencing increasing potential exposure, a deeper scientific look into the potential and real impacts of GBH applications on these protected species is undoubtedly necessary.

The exposure potential we considered in this study is based on migrating terrestrial life stages of amphibian populations. In the northeastern plains of Germany, approximately $25 \%$ of breeding ponds are located within crop fields, and another $25 \%$ of ponds are directly adjacent to field edges (Berger et al., 2011). The reported increase in the areas where GLY is applied and the changes in application schemes and crops over the last 20 years not only meet amphibians on land but also increase the risk of breeding ponds being contaminated by GLY. This may entail adverse effects on eggs and larvae (Relyea, 2005; Wagner et al., 2013). Additionally, indirect adverse effects on amphibians that are related to GLY may occur. For instance, GLY completely controls and removes green biomass, and it interferes with regulative interactions and food webs and likely changes food provisions for a wide range of wild-living organisms, including amphibians (Govindarajulu, 2008; Geiger et al., 2010; Pérez et al., 2011; Jahn et al., 2014).

\section{CONCLUSIONS}

Glyphosate usage in German agriculture has changed considerably over the 20-year study period. Our analysis investigated how wild-living amphibians present in fields were likely to be increasingly exposed to GLY during this time. For the environmental risk assessment and regulation of plant protection products, we advocate considering not only the state and usage of pesticides at the time of their authorization but also the changes in application schemes and extents over time.

\section{REFERENCES}

Baier, F., Jedinger, M., Gruber, E., and Zaller, J. G. (2016). Temperature seems to be an important factor when assessing effects of a glyphosate-based herbicide on egg and tadpole growth of Common toads (Bufo bufo; Amphibia L.). Front. Environ. Sci. 4:51. doi: 10.3389/fenvs.2016.00051

BCPC (2003). Pesticide Manual. British Crop Protection Council. 13. Auflage 2003, 514 page., S. 514: "Commercialisation: History: Herbicidal activity reported by D.D. Baird et al. (Proc. North Cent. Weed Control Conf., 1976, 26, 64). The isopropylamine, sodium and ammonium salts introduced by Monsanto Co. in 1974; the trimesium (trimethylsulfonium) salt introduced in Spain (1989) by ICI Agrochemicals (now Syngenta AG). Patents US 3799758 (to Monsanto); EP 53871; US 4315765 (both to ICI)“

Beckie, H. (2006). Herbicide-resistant weeds: managent tactics and practices. Weed Technol. 20, 793-814. doi: 10.1614/WT-05-084R1.1

Belden, J., McMurry, S., Smith, L., and Reilley, P. (2010). Acute toxicity of fungicide formulations to amphibians at environmentally relevant concentrations. Environ. Toxicol. Chem. 29, 2477-2480. doi: 10.1002/etc.297

Berger, G., Graef, F., and Pfeffer, H. (2013). Glyphosate applications on arable fields considerably coincide with migrating amphibians. Sci. Rep. 3:2622. doi: $10.1038 /$ srep02622

Berger, G., Pfeffer, H., and Kalettka, T. (eds). (2011). Amphibienschutz in Kleingewässerreichen Ackerbaugebieten (Conservation of Amphibians in Agricultural Landscapes Rich in Small Water Bodies). Rangsdorf: Natur \& Text.

Bernal, M. H., Solomon, K. R., and Carrasquilla, G. (2009). Toxicity of formulated glyphosate (Glyphos) and Cosmo-Flux to larval and juvenile Colombian frogs
Thus, we recommend conducting periodical reassessments of environmental risks-not only on the toxicity to organisms but also on the present and practical usage modes in agriculture that affect potential exposure patterns.

\section{AUTHOR CONTRIBUTIONS}

GB: Main organisor of the study, data analysis and manuscript writing. FG: Major expertise contributor, data analysis, and manuscript writing. BP: Major expertise contributor, data analysis, and manuscript writing. JH: Expertise contributor, data provision and analysis, and manuscript writing. CB: Expertise contributor, data generation, provision and analysis, and manuscript writing. NW: Expertise contributor, data provision and analysis, and manuscript writing.

\section{FUNDING}

This project was funded by the Umweltbundesamt, Germany under the award number FKZ: 370965421.

\section{ACKNOWLEDGMENTS}

We thank Dietmar Rossberg from the Federal Research Centre for Cultivated Plants, Kleinmachnow, Germany for contributing to the expert estimations and Horst-Henning Steinmann for additional explanations on the paper that were fundamental for our work. The Federal Office for Consumer Protection and Food Safety, and Mirijam Seng in particular, provided additional data on the GLY sales in Germany. The authors also thank Ulrich Stachow, Harald Kaechele, and Peter Zander for their comments on the manuscript.
2. Field and laboratory microcosm acute toxicity. J. Toxicol. Env. Health A 72, 966-973. doi: 10.1080/15287390902929717

Biga, L. M., and Blaustein, A. R. (2013). Variations in lethal and sublethal effects of cypermethrin among aquatic stages and species of anuran amphibians. Environ. Toxicol. Chem. 32, 2855-2860. doi: 10.1002/et c. 2379

Boone, M. D., Cowman, D., Davidson, C., Hayes, T., Hopkins, W., Relyea, R. A., et al. (2007). "Evaluating the role of environmental contamination in amphibian population declines," in Amphibian Conservation Action Plan. eds C. Gascon, J. P. Collins, R. D. Moore, D. R. Church, J. E. McKay, and J. R. I. Mendelson (Gland and Cambridge: IUCN/SSC Amphibian Specialist Group), 32-36.

Brausch, J. M., Beall, B., and Smith, P. N. (2007). Acute and sub-lethal toxicity of three polyethoxylated alkylamine surfactant formulations to Daphnia magna. Bull. Environ. Contam. Tox. 78, 510-514. doi: 10.1007/s00128-0079091-0

Brausch, J. M., and Smith, P. N. (2007). Toxicity of three polyethoxylated tallowamine surfactant formulations to laboratory and field collected fairy shrimp, Thamnocephalus platyurus. Arch. Environ. Contam. Toxicol. 52, 217-221. doi: 10.1007/s00244-006-0151-y

Brühl, C. A., Schmidt, T., Pieper, S., and Alscher, A. (2013). Terrestrial pesticide exposure of amphibians: an underestimated cause of global decline? Sci. Rep. 3:1135. doi: $10.1038 /$ srep01135

BVL (2009). Berichte zu Pflanzenschutzmitteln. Wirkstoffe in Pflanzenschutzmitteln, Zulassungshistorie und Regelungen der PflanzenschutzAnwendungsverordnung. Available online at: http://www.bvl.bund.de/ 
SharedDocs/Downloads/04_Pflanzenschutzmittel/bericht_WirkstoffeInPSM_ 2009.html?nn=1401286 (Accessed Dec 16, 2014)

BVL (2014c). Sales of Plant Protection Products in Germany. Statistics According to $\$ 19$ Plant Protection Act (PflSchG) for Years 2009-2013. Federal Office for Consumer Protection and Food Safety Braunschweig. Available online at: http://www.bvl.bund.de/DE/04_Pflanzenschutzmittel/01_Aufgaben/02_ ZulassungPSM/03_PSMInlandsabsatzExport/psm_PSMInlandsabsatzExport_ node.html (Accessed Dec 15, 2014)

BVL (2014a). Application Rules of Glyphosate, 21.05.2014. Available online at: http://www.bvl.bund.de/DE/04_Pflanzenschutzmittel/05_Fachmeldungen/ 2014/2014_05_21_Fa_Neue_Anwendung_Glyphosat.html?nn=1400938 (Accessed Nov 11, 2015)

BVL (2014b). Sale of Organo-Phosphorous Herbicide Active Substances (Glyphosate and Glyphosinate) for 1988-2008 in Germany. Braunschweig: Federal Office for Consumer Protection and Food Safety.

Cauble, K., and Wagner, R. S. (2005). Sublethal effects of the herbicide glyphosate on amphibian metamorphosis and development. Bull. Environ. Contam. Tox. 75, 429-435. doi: 10.1007/s00128-005-0771-3

Collins, J. P., and Storfer, A. (2003). Global amphibian declines: sorting the hypotheses. Divers. Distrib. 9, 89-98. doi: 10.1046/j.1472-4642.2003.00012.x

Cook, S., Wynn, S., and Clarke, J. (2010). Glyphosate - a necessary herbicide. How valuable is glyphosate to UK agriculture and environment? Outlooks Pest Manag. 21, 280-283.

de Silva, A. (2009). The Incidence and Pattern of Malformations, Abnormalities, Injuries, and Parasitic Infection of Amphibians in Sri Lanka (Preliminary Findings). Final Report. Amphibian Specialists Group, Washington DC.

Destatis (2011). Land- und Forstwirtschaft, Fischerei. Bodenbearbeitung, Bewässerung, Landschaftselemente. Erhebung über Landwirtschaftliche Produktionsmethoden (ELPM), 2010. Fachserie 3, Heft 5. Wiesbaden: Statistisches Bundesamt.

Destatis (2015). Mais https://www.destatis.de/DE/ZahlenFakten/ Wirtschaftsbereiche/LandForstwirtschaftFischerei/FeldfruechteGruenland/ Tabellen/FeldfruechteZeitreihe.html (Accessed Nov 02, 2015)

Dill, G. M., Sammons, R. D., Feng, P. C. C., Kohn, F., Kretzmer, K., Mehrsheikh, A., et al. (2010). "Glyphosate: discovery, development, applications, and properties," in Glyphosate Resistance in Crops and Weeds, ed V. K. Nandula (Hoboken, NJ: John Wiley \& Sons), 1-33.

Dinehart, S. K., Smith, L. M., McMurry, S. T., Anderson, T. A., Smith, P. N., and Haukos, D. A. (2009). Toxicity of a glufosinate- and several glyphosate based herbicides to juvenile amphibians from the Southern High Plains, USA. Sci. Total Environ. 407, 1065-1071. doi: 10.1016/j.scitotenv.2008.10.010

Duke, S. O., and Powles, S. B. (2008). Glyphosate: a once-in-a-century herbicide. Pest Manag. Sci. 64, 319-325. doi: 10.1002/ps.1518

Edge, C. B., Gahl, M. K., Pauli, B. D., Thompson, D. G., and Houlahan, J. E. (2011). Exposure of juvenile green frogs (Lithobates clamitans) in littoral enclosures to a glyphosate-based herbicide. Ecotoxicol. Environ. Saf. 74, 1363-1369. doi: 10.1016/j.ecoenv.2011.04.020

Edge, C. B., Gahl, M. K., Thompson, D. G., and Houlahan, J. E. (2013). Laboratory and field exposure of two species of juvenile amphibians to a glyphosatebased herbicide and Batrachochytrium dendrobatidis. Sci. Total Environ. 444, 145-152. doi: 10.1016/j.scitotenv.2012.11.045

EU (1992). Council directive 92/43/EEC of 21 May 1992 on the conservation of natural habitats and of wild fauna and flora. Off. J. 206, 7-50.

Geiger, F., Bengtsson, J., Berendse, F., Wolfgang, W. W., Emmerson, M., Morales, M. B., et al. (2010). Persistent Negative Effects of Pesticides on Biodiversity and Biological Control Potential on European Farmland. Basic Appl. Ecol. 11, 97-105. doi: 10.1016/j.baae.2009.12.001

Giesy, J. P., Dobson, S., and Solomon, K. R. (2000). Ecotoxicological risk assessment for Roundup herbicide. Rev Environ Contam Toxicol 167, 35-120. doi: 10.1007/978-1-4612-1156-3_2

Govindarajulu, P. P. (2008). Literature Review of Impacts of Glyphosate Herbicide on Amphibians: What Risks can the Silvicultural Use of this Herbicide Pose for Amphibians in B.C.? Wildlife Report No. R-28 B.C. Ministry of Environment, Victoria, BC.

Güngördü, A., Uçkun, M., and Yologlu, E. (2016). Integrated assessment of biochemical markers in premetamorphic tadpoles of three amphibian species exposed to glyphosate-and methidathion-based pesticides in single and combination forms. Chemosphere 144, 2024-2035. doi: $10.1016 /$ j.chemosphere.2015.10.125

Hayes, T. B., Case, P., Chul, S., Chung, D., Haeffele, C., Haston, K., et al. (2006). Pesticide mixtures, endocrine disruption, and amphibian declines: are we underestimating the impact? Environ. Health Perspect. 114, 40-50. doi: 10.1289/ehp. 8051

Hegde, G., and Krishnamurthy, S. V. (2014). Analysis of health status of the frog Fejervarya limnocharis (Anura: Ranidae) living in rice paddy fields of Western Ghats, using body condition factor and AChE content. Ecotoxicol. Environ. Contaminat. 9, 69-76. doi: 10.5132/eec.2014.01.009

Howe, C. M., Berrill, M., Pauli, B. D., Helbing, C. C., Werry, K., and Veldhoen, N. (2004). Toxicity of glyphosate-based pesticides to four North American frog species. Environ. Toxicol. Chem. 23, 1928-1938. doi: 10.1897/03-71

Jahn, T., Hoetker, H., Oppermann, R., Bleil, R., and Vele, L. (2014). Protection of Biodiversity of Free Living Birds and Mammals in Respect of the Effects of Pesticides. Umweltbundesamt. Available online at: https://www. umweltbundesamt.de/sites/default/files/medien/378/publikationen/texte_30_ 2014 protection of biodiversity.pdf

Lajmanovich, R. C., Attademo, A. M., Simoniello, M. F., Poletta, G. L., Junges, C. M., Peltzer, P. M., et al. (2015). Harmful Effects of the Dermal Intake of Commercial Formulations Containing Chlorpyrifos, 2, 4-,D, and Glyphosate on the Common Toad Rhinella arenarum (Anura: Bufonidae). Water Air Soil Pollut. 226:427. doi: 10.1007/s11270-015-2695-9

Lötters, S., Filz, K. J., Wagner, N., Schmidt, B. R., Emmerling, C., and Veith, M. (2014). Hypothesizing if responses to climate change affect herbicide exposure risk for amphibians. Environ. Sci. Europe 26:31. doi: 10.1186/s12302-014-0031-4

Mann, R. M., and Bidwell, J. R. (1999). The toxicity of glyphosate and several glyphosate formulations to four species of southwestern Australian frogs. Arch. Environ. Contam. Toxicol. 36, 193-199. doi: 10.1007/s002449900460

Mann, R. M., Hyne, R. V., Choung, C. B., and Wilson, S. P. (2009). Amphibians and agricultural chemicals: review of the risks in a complex environment. Environ. Pollut. 157, 2903-2927. doi: 10.1016/j.envpol.2009.05.015

Marco, A., Cash, D., Belden, L. K., and Blaustein, A. R. (2001). Sensitivity to urea fertilizationin three amphibian species. Arch. Environ. Contam. Toxicol. 40, 406-409. doi: 10.1007/s002440010190

McComb, B. C., Curtis, L., Chambers, C. L., Newton, M., and Bentson, K. (2008). Acute toxic hazard evaluations of glyphosate herbicide on terrestrial vertebrates of the Oregon coast range. Environ. Sci. Pollut. Res. 15, 266-272. doi: 10.1065/espr2007.07.437

Miller, A., Gervais, J. A., Luukinen, B., Buhl, K., and Stone, D. (2010) Glyphosate Technical Fact Sheet; National Pesticide Information Center, Oregon State University Extension Services. Available online at: http://npic.orst.edu/ factsheets/glyphotech.pdf (Accessed Dec 05, 2016).

Moore, L. J., Fuentes, L., Rodgers, J. H., Bowerman, W. W., Yarrow, G. K., and Chao, W. Y. (2012). Relative toxicity of the components of the original formulation of Roundup to five North American anurans. Ecotoxicol. Environ. Saf. 78, 128-133. doi: 10.1016/j.ecoenv.2011.11.025

Nail, E. L., Young, D. L., and Schillinger, W. F. (2007). Diesel and glyphosate price changes benefit the economics of conservation tillage versus traditional. Tillage. Soil Till. Res. 94, 321-327. doi: 10.1016/j.still.2006.08.007

Oldham, R. S., Latham, D. M., Hilton Brown, D., Towns, M., Cooke, A. S., and Burn, A. (1997).The effect of ammonium nitrate fertiliser on frog (Rana temporaria) survival. Agric. Ecosyst. Environ. 61, 69-74. doi: 10.1016/S0167-8809(96)01095-X

Pérez, G. L., Vera, M. S., and Miranda, L. (2011). Effects of Herbicide Glyphosate and Glyphosate-Based Formulations on Aquatic Ecosystems, Herbicides and Environment, Dr Andreas Kortekamp (Ed.), ISBN: 978-953-307-476-4, InTech, Available online at: http://www.intechopen.com/books/herbicidesandenvironment/effects-of-herbicide-glyphosate-and-glyphosate-basedformulations-on-aquatic-ecosystems

Quaranta, A., Bellantuono, V., Cassano, G., and Lippe, C. (2009). Why amphibians are more sensitive than mammals to xenobiotics. PLoS ONE 4:e7699. doi: 10.1371/journal.pone.0007699

Raubuch, M., and Schieferstein, B. (2002): Ökologische und ökosystemanalytische Ansätze für das Monitoring von gentechnisch veränderten Organismen. Berlin: Umweltbundesamt. 
Relyea, R. A. (2005). The lethal impact of Roundup on aquatic and terrestrial amphibians. Ecol. Applic. 15, 1118-1124. doi: 10.1890/04-1291

Relyea, R. A. (2009). A cocktail of contaminants: how mixtures of pesticides at low concentrations affect aquatic communities. Oecologia 159, 363-376. doi: 10.1007/s00442-008-1213-9

Relyea, R. A. (2011). "Amphibians are not ready for Roundup ${ }^{\circledR}$," in Wildlife Ecotoxicology, Vol 3 Emerging Topics in Ecotoxicology, eds J. E. Elliott, C.A. Bishop, and C. A. Morrissey (New York, NY: Springer), 267-300.

Rissoli, R. Z., Abdalla, F. C., Costa, M. J., Rantin, F. T., McKenzie, D. J., and Kalinin, A. L. (2016). Effects of glyphosate and the glyphosate based herbicides Roundup Original ${ }^{\circledR}$ and Roundup Transorb ${ }^{\circledR}$ on respiratory morphophysiology of bullfrog tadpoles. Chemosphere 156, 37-44. doi: 10.1016/j.chemosphere.2016.04.083

Rossberg (2015a). Use of POEA Free Glyphosate-Based Formulations in German Agriculture. Personal communication, Kleinmachnow.

Rossberg (2015b). Use of Glyphosate in Germany by Professional Users Apart from Agriculture for Year 2012. Personal communication, Kleinmachnow.

Soloneski, S., Ruiz de Arcaute, C., and Larramendy, M. L. (2016). Genotoxic effect of a binary mixture of dicamba-and glyphosate-based commercial herbicide formulations on Rhinella arenarum (Hensel, 1867) (Anura, Bufonidae) latestage larvae. Environ. Sci. Pollut. Res. 23, 17811-17821.

Steinmann, H. H., Dickeduisberg, M., and Theuvsen, L. (2012). Uses and benefits of glyphosate to German arable farming. Crop Protec. 42. 164-169. doi: 10.1016/j.cropro.2012.06.015

Steinmann, H. H., and Dobers, E. S. (2013). Spatio-temporal analysis of crop rotations and crop sequence patterns in Northern Germany: potential implications on plant health and crop protection. J. Plant Dis. Prot. 120, 85-94. doi: 10.1007/BF03356458

Stuart, S. N., Hoffmann, M., Chanson, J. S., Cox, N. A., Berridge, R. J., Ramani, P., et al. (2008). Threatened Amphibians of the World. Barcelona: Lynx Editions.

Vincent, K., and Davidson, C. (2015). The toxicity of glyphosate alone and glyphosate-surfactant mixtures to western toad (Anaxyrus boreas) tadpoles. Environ. Toxicol. Chem. 34, 2791-2795. doi: 10.1002/ etc. 3118

Wagner, N., and Lötters, S. (2013). Possible Correlation of the Worldwide Amphibian Decline and the Increasing Use of Glyphosate in the Agrarian Industry. - BfN-Skripten 343. Bonn: Bundesamt für Naturschutz.

Wagner, N., Reichenbecher, W., Teichmann, H., Tappeser, B., and Lötters, S. (2013). Questions concerning the potential impact of glyphosatebased herbicides on amphibians. Environ. Toxicol. Chem. 32, 1688-1700. doi: $10.1002 /$ etc. 2268

Weedscience (2015). International Survey of Herbicide Resistant Weeds. Available online at: http://www.weedscience.org/summary/home.asp (Accessed Jan 26, 2015)

Xu, Q., and Oldham, R. S. (1997). Lethal and sublethal effects of nitrogen fertilizer ammonium nitrate on Common toad (Bufo bufo) tadpoles. Arch. Environ. Contam. Toxicol. 32, 298-303.

Yadav, S. S., Giri, S., Singha, U., Boro, F., and Giri, A. (2013). Toxic and genotoxic effects of Roundup on tadpoles of the Indian skittering frog (Euflictis cyanophlyctis) in the presence and absence of predator stress. Aquat. Toxicol. 132-133, 1-8. doi: 10.1016/j.aquatox.2013.01.016

Conflict of Interest Statement: The authors declare that the research was conducted in the absence of any commercial or financial relationships that could be construed as a potential conflict of interest.

The reviewer AG and handling editor declared their shared affiliation.

Copyright (c) 2018 Berger, Graef, Pallut, Hoffmann, Brühl and Wagner. This is an open-access article distributed under the terms of the Creative Commons Attribution License (CC BY). The use, distribution or reproduction in other forums is permitted, provided the original author(s) and the copyright owner are credited and that the original publication in this journal is cited, in accordance with accepted academic practice. No use, distribution or reproduction is permitted which does not comply with these terms. 